\title{
Demand-Driven Biogas Production from Anaerobic Digestion of Sewage Sludge: Application in Demonstration Scale
}

\author{
Mauro Lafratta ${ }^{1,2}$ (D) $\cdot$ Rex B. Thorpe ${ }^{3} \cdot$ Sabeha K. Ouki $^{4} \cdot$ Achame Shana $^{5} \cdot$ Eve Germain $^{2} \cdot$ Mark Willcocks $^{6}$. \\ Jacquetta Lee ${ }^{1}$
}

Received: 30 October 2020 / Accepted: 15 April 2021 / Published online: 1 May 2021

(c) The Author(s) 2021

\begin{abstract}
The power system needs flexible electricity generators. Whilst electricity generation from anaerobic digestion (AD) of sewage sludge has traditionally been baseload, transforming the generation capacity into a modern flexible operator is an opportunity to further valorise the resource. This work aims to demonstrate that $\mathrm{AD}$ of sewage sludge can support flexible generation and be operated dynamically in a relevant operational environment, to promote full scale implementation. A demonstration scale plant $\left(20 \mathrm{~m}^{3}\right.$ conventional $\mathrm{AD}$ reactors $)$ was used to test several feeding regimes designed to return a biogas production rate that matches the demand. Two demand profiles are defined, either by common corporate power purchase agreements or by the main balancing mechanism used by the grid operator in UK. Demand-driven biogas production is demonstrated in this relevant operational environment, and the flexibilisation performance is positive in all scenarios. The value of the biogas increases by up to $2 \%$, which outperforms the results obtained at pilot scale. Additionally, an increase in biogas yield is observed. Whilst transitional imbalances are recorded, they last for few hours and the overall stability is not affected. In conclusion, these trials demonstrate demand-driven biogas production is a feasible operational solution and full-scale implementation is possible.
\end{abstract}

\section{Graphical Abstract}

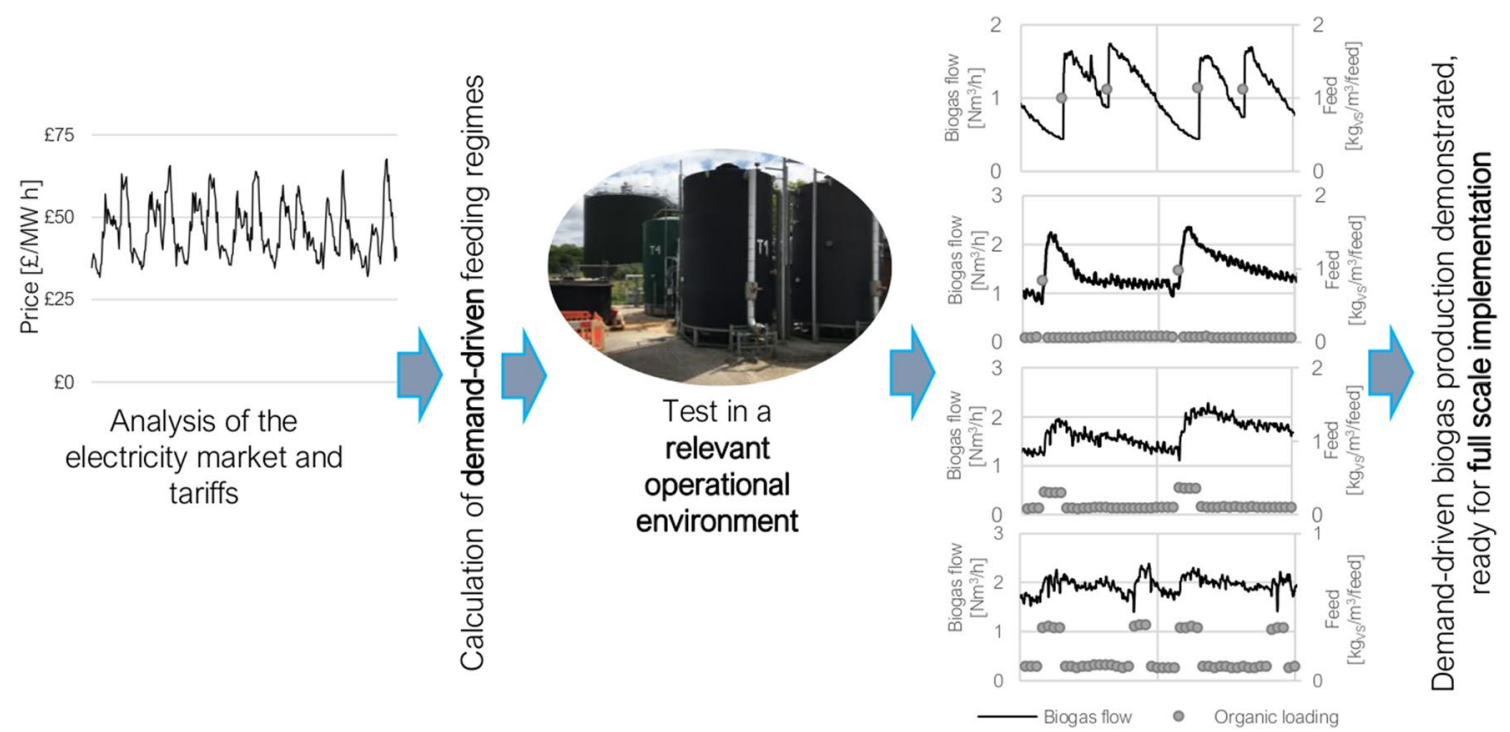

Keywords Anaerobic Digestion · Sewage sludge $\cdot$ Flexible electricity generation · Demand-driven biogas production · Demonstration scale

Extended author information available on the last page of the article 


\section{Statement of Novelty}

Modern renewable flexible electricity generators are needed in the transition of the power grid towards a decarbonised system. Electricity generation from anaerobic digestion of sewage sludge can be made flexible, and demand-driven biogas production can support this. Demand-driven biogas production is an innovative operational solution to valorise sewage sludge as a resource and provide the additional service of flexible electricity generation. Previous pilot scale experiments show the technical feasibility, and the validation at demonstration scale presented in this paper paves the way for transferring the knowledge and putting the solution in practice at full scale.

\section{Introduction}

The valorisation of organic waste streams and their conversion into resources is an established practice in many industries. For example, the water industry uses Anaerobic Digestion (AD) as a process to treat the organic waste in sewage sludge, the main by-product of sewage treatment in Sewage Treatment Works (STW). While achieving the main objective of reducing the pathogens and solids contents, $\mathrm{AD}$ allows the recovery of nutrients while recovering energy at the same time [1,2]. The energy recovered in the form of biogas is generally used on-site for electricity and heat generation, allowing the valorisation of sewage sludge as a resource.

In UK, in recent years, the use of $\mathrm{AD}$ has increased significantly, mainly due to incentivisation schemes for the generation of electricity from renewable sources. These schemes aimed to support the installation of generation capacity from renewable sources by increasing the value of the resource over the market value. Whilst these schemes have been successful also in incentivising power plants from biomass including sewage sludge [1], most of this capacity was from wind and solar power generation, two sources inherently intermittent and weather dependent. This constitutes a strain on the power system and the security of electricity supply is threatened by a large use of such intermittent renewable energy sources.

Other technologies, preferably renewable, are needed to provide on-demand electricity generation to support the balance of demand and supply on the grid. Electricity generation from biomass and other bioenergy sources, such as biogas from $\mathrm{AD}$, is seen as a potential provider of such on-demand electricity generation [3]. The request for on-demand electricity generation occurs with long-or short-term notice [4]. Some trading platforms or balancing services have a few hours' notice between request and delivery, making the demand for electricity generation predictable; this is the case for what is defined in this work as dispatchable generation. Some other balancing services are generally unpredictable and have few minutes' notice between the request and the delivery; this is the case for flexible electricity generation.

Seeking to demonstrate the technical feasibility in a realistic environment to operate the $\mathrm{AD}$ of sewage sludge to generate electricity that can match the dispatchable or flexible demand, such variable targeted biogas production is defined in this work as 'demand-driven'. Demand-driven biogas production could add further value to sewage sludge as a renewable energy source by allowing it to provide the additional service of supporting dispatchable or flexible electricity generation.

While AD is often operated in steady state, which returns a steady biogas production rate, pilot scale research show that $\mathrm{AD}$ of sewage sludge can produce biogas on demand [5]. Experiments in $60 \mathrm{~L}$ reactors were carried out in fully automated rigs in conventional and advanced digestion. These reactors are continuous stirred tank reactors (CSTRs), with active volume controlled at $50 \mathrm{~L}$. Reactors were fed at different loading conditions (standard at $2.5 \mathrm{~kg} \mathrm{vs} / \mathrm{m}^{3} / \mathrm{d}$ and high at $4 \mathrm{~kg}_{\mathrm{vS}} / \mathrm{m}^{3} / \mathrm{d}$ ) with a substrate made of controlled composition of raw primary and surplus activated sludge. In the case of advanced digestion, the substrate was treated with thermal hydrolysis before AD. Another pilot-scale study, despite using a technology not commonly used in industrial applications, also provides insights in demand-driven biogas production from AD of sewage sludge [6]. However, the suitability demonstrated at pilot scale requires further steps before full-scale application. Despite AD of sewage sludge is extensively used in the water industry globally, no published literature is available regarding the application of demand-driven biogas production at larger scale than pilot.

Whilst obtaining demand-driven biogas production from AD of sewage sludge for dispatchable and flexible electricity generation is demonstrated at pilot scale, a fundamental question is to be answered: is this operational solution technically feasible and beneficial in a relevant operational environment?

To inform full-scale application, the intermediate step of proving technical feasibility at demonstration scale is fundamental. Relevant available literature is limited to previous work by Mauky et al. [7], which investigated demand-driven biogas production in a larger environment than pilot, successfully implemented such operational solution. However, significant differences are found with the scope of this work: the substrate used is not sewage sludge, the reactors are CSTRs, which is a rare configuration in the water industry, and the size is significantly smaller than the usual full-scale size used by the water industry. Additionally, the targeted 
demand is limited to a dispatchable electricity generation and does not encompass the more restrictive flexible generation, specifically investigated in this work. Therefore, the novelty of this work lies on focussing on an experimental programme and environment never investigated before.

Whilst previous pilot scale experiments [5] provide useful insights, there are several important differences with full scale reactors, including:

- The feeding is operated as pulse feeding in pilot scale, while in full scale it is often operated in hourly batches. The storage of a volume of sewage sludge equal to a several hours of average throughput is often not feasible at full scale due to land and volume requirements.

- The mixing is provided by a stirrer in pilot scale, but this is a technology rarely used in full scale in the water industry. Most often mixing is provided by external recirculation in full scale considering maintenance requirements.

- The heating is provided by a heating jacket in pilot scale, whereas by an external heat exchanger in full scale.

In particular, the good mixing conditions of pilot scale may affect the results by providing faster mixing between substrate and bacteria, therefore decreasing the lag time between the feed and the peak of biogas production, and by reducing the phenomena of foaming or gas lifting. Foaming is often found in larger scale digesters in the case of poor or excessive mixing or in the case of excessive or erratic feeding [8].

The aim of this work is to trial appropriately designed demand-driven feeding regimes in a relevant operational environment at demonstration scale and understand if the results obtained from pilot scale experiments are replicable in a larger scale environment. This work also aims to investigate whether demand-driven biogas production from $\mathrm{AD}$ of sewage sludge provides a beneficial effect, which increase the value of the resource in comparison to usual steady-state operation.

\section{Material and Methods}

The trials were run in a demonstration scale plant with reactors of $20 \mathrm{~m}^{3}$ total volume presented in Sect. Equipment. The digesters run with operational conditions similar to full scale digesters, as feeding is semi-continuous and mixing is provided by external recirculation. The trials are operated in conventional $\mathrm{AD}$, as this was found in pilot scale to be more demanding for $\mathrm{AD}$ when compared to advanced $\mathrm{AD}$.

Two kind of experiments were operated. An initial test adopted the same pulse feeding regime calculated for the case of flexible generation used at pilot scale [5]. The objective of this initial test is to investigate the effects of the realistic mixing technology and quality to the biogas production rate and investigate the scalability of the results obtained at pilot scale. The second and main test involved the test of demand-driven feeding regimes under semi-continuous hourly feeding. The feeding regimes were calculated according to the analysis of the electricity market and tariffs in Sect. Performance and Stability Parameters.

\section{Equipment}

A demonstrative scale plant available at Thames Water's research, development and innovation facilities was used for this work. Although the plant has previously been outlined by Rus et al. [9] and Mills [10], all relevant technical details modified by this work or not previously published are provided in this section. Despite being located in an industrial STW, the demonstration plant is not connected to the sludge stream of the STW; therefore, sewage sludge is imported by road tankers. Tanks T1 and T2 are typically used for imports of Primary Sludge (PS) and Surplus Activated Sludge (SAS) respectively and blended in an intermediate blending tank T3. Sewage sludge stored in these three tanks is mixed by recirculation (10 min per hour) and air mixing (10 min per hour) to avoid stratification and limit the occurrence of possible anaerobic processes. However, the tanks are not cooled. The recirculation line of $\mathrm{T} 3$ is also fitted with a macerator to break up rag and other solids that could block pumps and pipework of the digesters or affect the digestion process and active volume. Tanks T4 and T5 are the two digesters, fitted with external recirculation and heat exchangers. The digesters' sludge (the solid-liquid mixture withdrawn from the digesters) is collected in an intermediate T6 and then discharged to the head of the STW in batches. The biogas is collected from the headspace on top of the digesters, measured and conveyed to two separate gas holders at controlled pressure. The full diagram is shown in Fig. 1. Other stages and equipment available at the same plant were not used in this project.

The process is controlled with a Supervisory Control And Data Acquisition (SCADA) system. The original system was appropriately modified for the scope of this project to have the withdrawal of digester sludge and the feed of fresh sewage sludge to occur at the same time, and to allow the operator to set different feed volumes for each hourly feed.

The hourly volumes of feed are set according to the conditions presented in 2.2 and the feeding regimes calculated in 2.4. SCADA automatically calculates the pump running time to feed the volume set, according to the setpoint value of flow speed, which is routinely calibrated by the operator. A similar procedure is followed for the pump running time for the withdrawal of digester sludge. The actual feeding speed is measured by electromagnetic 
Fig. 1 Diagram of the plant. For the use of tanks T1, T2, T3, T4, T5, T6, GH4 and GH5 refer to text. Pipework connections, position of pumps $(\mathrm{P})$, macerator $(\mathrm{M})$ and heat exchangers $(\mathrm{H})$ are reported in the diagram. The black lines refer to solid streams, while gray lines refer to gaseous streams

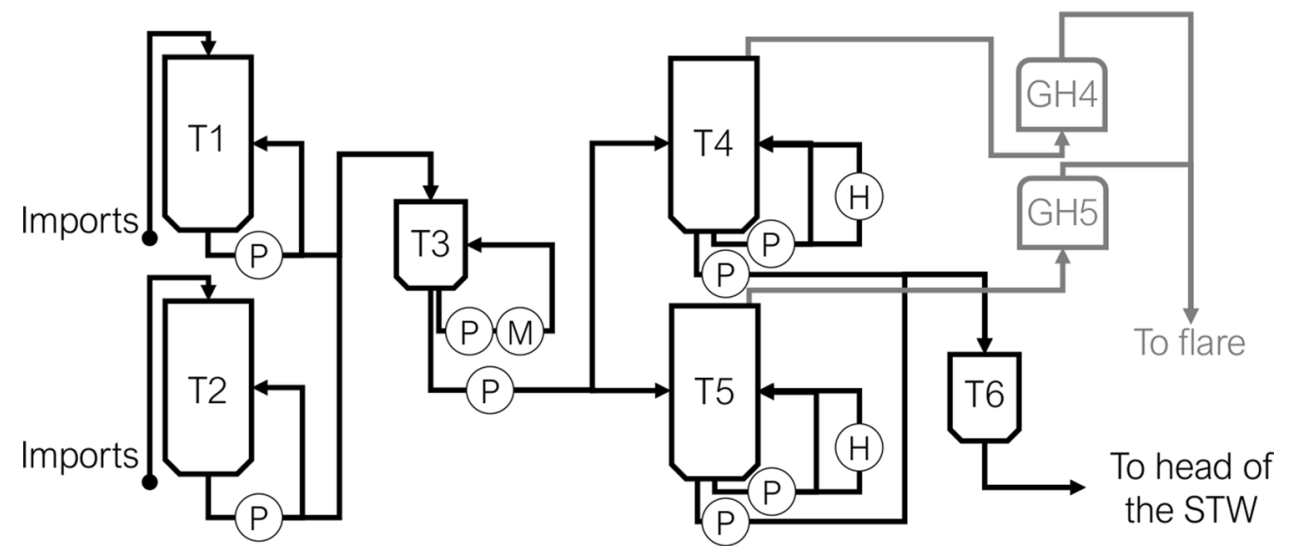

flowmeters (ABB FSM4000) and the actual volume fed calculated according to the pump running time. The figure of the actual volume fed is then multiplied by the measured organic content of the sewage sludge to obtain the organic volume fed.

Mixing is provided continuously by an external recirculation pump (Seepex progressive cavity pump BN 10-6LS, $2.2 \mathrm{~kW}$, set at $50 \%$ speed), which also support the heating of the digesters when a valve on the recirculation line is activates the connection with the heating exchanger. The heat is provided by the water heated by a boiler (Fulton EP30 hot water boiler, set at $55^{\circ} \mathrm{C}$ ). SCADA controls the heating cycle by monitoring the temperature in the digesters (measured by two temperature transmitters ABB TSP321 per digester, positioned at opposite sides) and starting the heating when the temperature is half degree lower than the setpoint $\left(39^{\circ} \mathrm{C}\right)$ and stopping it when the temperature is half degree higher than the setpoint. The temperature of $39^{\circ} \mathrm{C}$ is defined as the maximum temperature at which the whole demonstration plant has been found to reliably operate.

The biogas flow is measured with thermal mass flow meters (Magnetrol Thermatel Enhanced, Model TA2), calibrated at the beginning of the trial by the manufacturer for digester gas (methane 65\% and carbon dioxide 35\%). During the trial, the monitoring of the quality of the measurement did not motivate additional calibrations as the experiments lasted only 9 months, and common industrial practice suggests calibrating these instruments every 5 years. The measurement is performed continuously, and data recorded every second. The recorded measurements are then averaged to obtain a two minutes interval between two datapoints. The biogas flow is measured at standard temperature and pressure conditions and then calculated at normal conditions [11, 12] based on the gas laws. The datapoints are then presented with a 5-points median signal filter [13]. Additionally, days and time are also adjusted to present the daily periods in realistic times, while the experimental activities run on times to facilitate the monitor and control of the peak time feeds during regular working hours.
The gauge pressure in the headspace of the digesters and along the gas line and gas holders (GH4 and GH5 in Fig. 1) is kept constant at $1000 \mathrm{~Pa}$. A $10 \mathrm{~cm}$ column of water or an $8.5 \mathrm{~cm}$ column of a water saturated with salt $(26.3 \%$ weight, at $20{ }^{\circ} \mathrm{C}$ ) imposes the pressure at the outflow from the gas holders, thereby defining the pressure in the whole system. The pressure in the gas line is measured by pressure transmitters (ABB series $2600 \mathrm{~T}$, model 266HSH). The gas holders are fitted with a floating roof each, which allows a variable volume of gas to be stored and accommodate the difference between the dynamic inflow from the digesters and the steadier outflow.

Foaming is an important operational parameter and a safety concern. Whilst some foam is generally present in the digesters, an increase in its level may overflow in the gas line, damage instrumentation and cause several operational issues [14].

To monitor the effects of demand-driven feeding regimes to the foam level, this is calculated as the difference between the liquid digester level measured by differential pressure transmitter (ABB series $2600 \mathrm{~T}$, model 266DSH) and the digestate level measured by guided wave radar level transmitters (ABB MT5000), thereby assessing the level of digesters mainly occupied by biogas bubbles. A major foaming event is defined when the foamed digestate occupies the whole headspace of the digesters and spills into the gas line.

\section{Biochemical Characteristics}

The AD process in the digesters was started by seeding with digestate from full-scale conventional digesters.

The two kind of experiments are operated in the two reactors as follows:

- T4 at active volume of $16 \mathrm{~m}^{3}$ and fixed hydraulic retention time (HRT) of 16 days (pulse feeding experiments), and

- T5 at active volume of $18 \mathrm{~m}^{3}$ and the HRT adjusted to obtain the organic loading rate (OLR) of $2.5 \mathrm{~kg}_{\mathrm{vS}} / \mathrm{m}^{3} / \mathrm{d}$, 
accommodating for the variable organic content (semicontinuous feeding experiments).

The range of typical OLR for AD of sewage sludge is between 1.5 and $4.0 \mathrm{~kg}_{\mathrm{VS}} / \mathrm{m}^{3} / \mathrm{d}$ [15] and is an effective tool to control the process [16]. The OLR is the main parameter used to measure the organic matter fed to a reactor as the total amount of Volatile Solids (VS) fed in a specific period in a reactor with a defined active volume. The values of OLR $=2.5 \mathrm{~kg}_{\mathrm{VS}} / \mathrm{m}^{3} / \mathrm{d}$ and HRT $=16$ days are the most common desired conditions for conventional AD of sewage sludge [15].

As one of the objectives of the trial was to mirror the conditions of full-scale digesters, thickened and blended sewage sludge was imported from a STW. The organic content of the imported sewage sludge was measured during the whole experimental period to be $\mathrm{DS} \%=5.13 \pm 0.56 \%$ and $\operatorname{VS} \%$ (as $\mathrm{DS} \%)=71.37 \pm 5.37 \%$, giving a $\mathrm{VS} \%=3.66 \pm 0.34 \%$.

Consequently, the pulse feeding experiments, at fixed $\mathrm{HRT}=16$ days, were operated at an average OLR $=2.41 \pm 0.09 \mathrm{~kg}_{\mathrm{VS}} / \mathrm{m}^{3} / \mathrm{d}$.

In the semi-continuous feeding experiments, targeting a fixed OLR of $2.5 \mathrm{~kg}_{\mathrm{VS}} / \mathrm{m}^{3} / \mathrm{d}$, the HRT is used to accommodate the variability of DS\% and VS\%. Therefore, the average HRT resulted in $16.7 \pm 1.2$ days, achieving an average OLR $=2.60 \pm 0.04 \mathrm{~kg}_{\mathrm{VS}} / \mathrm{m}^{3} / \mathrm{d}$.

Considering the substrate is real substrate that is stored before being fed, acidification may naturally occur despite the mitigative measures fitted on the equipment reported in sect. "Equipment". This may lead to alteration of the substrate from fresh over time. In fact, an alteration of the substrate during the experimental period is observed. $\mathrm{pH}$ (measured potentiometrically [17]) and short-chain Volatile Fatty Acids (sc-VFAs) concentration (measured by gas chromatography [18]) are monitored as indicators of the quality of the substrate.

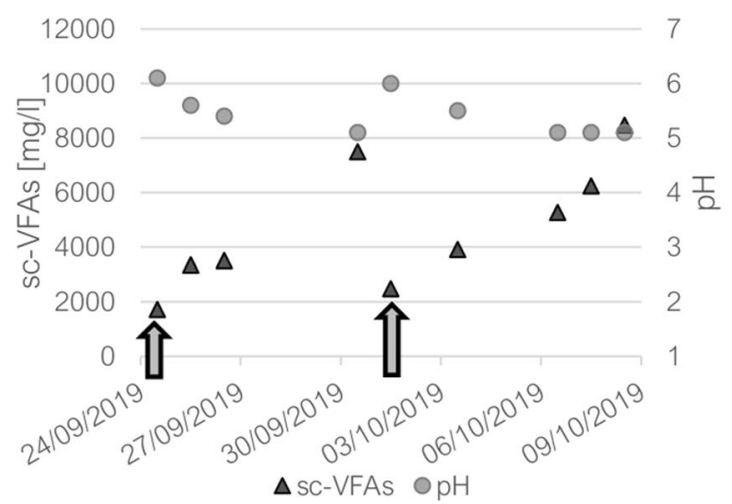

The ambient temperature appears to be an important factor in the alteration of the substrate. The graph on the left of Fig. 2 shows the alteration of the substrate after two imports (signposted by the arrows) before the experimental period. In periods of higher ambient temperatures, the quality of the substrate reaches sc-VFAs above $8000 \mathrm{mg} / \mathrm{l}$ and $\mathrm{pH}$ lower than 5.2, from reference values of fresh substrate of $\mathrm{sc}-\mathrm{VFAs}=3444 \pm 1886 \mathrm{mg} / \mathrm{l}$ and $\mathrm{pH}=5.9 \pm 0.4$.

The experimental activities presented in this work were carried out in winter months to mitigate the effects of the ambient temperature on the quality of the substrate. The average daily maximum and minimum ambient temperature during the period of experimental activities were respectively $9{ }^{\circ} \mathrm{C}$ and $3{ }^{\circ} \mathrm{C}$ [19]. The characteristics of the feed in this period are sc-VFAs $=5683 \pm 2,657 \mathrm{mg} / \mathrm{l}$ and $\mathrm{pH}=5.7 \pm 0.4$, shown as an example in Fig. 2-right.

\section{Performance and Stability Parameters}

As $\mathrm{AD}$ is a biochemical process that requires specific conditions to perform [20], and research show that with dynamic feeding transitional imbalances have to be expected $[5,7$, $21]$, the stability of the process is monitored. In particular, the parameters listed by Lafratta et al. [5] are used for routine monitoring by water companies such as Thames Water. The main parameters are the total VFAs concentration, the ratio of VFAs over total alkalinity and the $\mathrm{pH}$. In consideration of early warning parameters for the failure of the process, individual sc-VFAs are also monitored, as the concentration of ethanoic acid and the ratio of ethanoic and propanoic acid concentrations.

The performance of the AD process is usually monitored by means of several parameters, including:

- Dry Solids Destruction (DSD),

- Volatile Solids Destruction (VSD),

- Biogas yield.

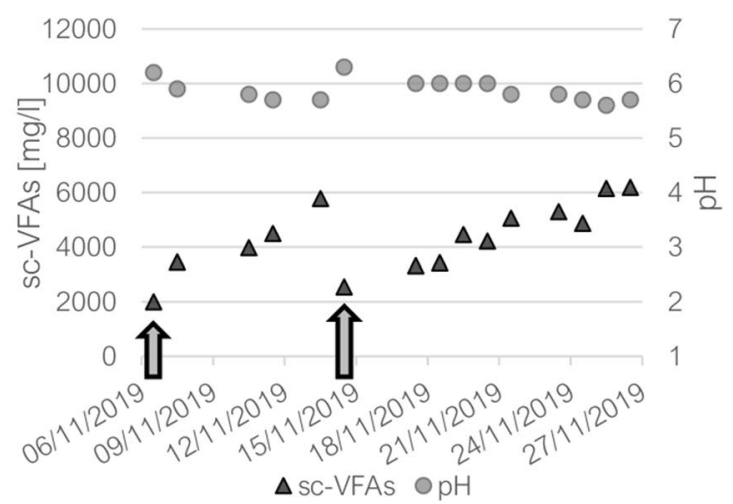

Fig. 2 Examples of the alteration of the substrate. The average maximum and minimum ambient temperature in the periods shown were $16{ }^{\circ} \mathrm{C}$ and $9{ }^{\circ} \mathrm{C}$ [19] (left) and $9{ }^{\circ} \mathrm{C}$ and $3{ }^{\circ} \mathrm{C}$ [19] (right) 
The DSD and VSD are calculated by mass balance, and the VSD is calculated also with the Van Kleeck method [22]. The biogas yield measures the amount of biogas produced per unit mass of substrate fed, measured both as DS and VS.

The performance of $\mathrm{AD}$ for flexibilisation is measured by means of two main parameters [5]. Firstly, the response measures the lag between the feeding event and the maximum of biogas production rate. Secondly, the length of the peak measures the period of time in which half of the total biogas produced between two consecutive feeds.

The ultimate performance parameter of demand-driven biogas production is the increase in value of the electricity produced from the biogas. The methodology for its calculation and assumptions made are previously presented in [5].

\section{Calculation of Feeding Regimes}

The crucial aspect of the valorisation of the biogas by adopting a demand-driven approach is the calculation of the feeding regimes [23]. The feeding regimes drive the AD process to produce the biogas at different rates, which need to match the variability of the demand over time. While the pulse feeding experiment adopts the same feeding regime previously calculated for flexible electricity generation at pilot scale [5], the different operational conditions of the semicontinuous feeding experiments require a full assessment of the demand.

In addition to the start time of the peak time feed, the length of this period is of crucial interest when operating hourly feeds. Therefore, the feeding regimes are calculated to consider an hourly interval between feeds and the length of peak times for each experimental condition. The full assessment of the demand to define the demand-driven feeding regimes is performed and presented in the following sub-sections.

\section{Dispatchable Generation}

The feeding regime for dispatchable generation is designed on the structure of most common commercial tariffs available on the market for large users, such as water companies. In Corporate Power Purchase Agreements (CPPA) the tariffs are agreed in advance than when the actual generation occurs. These tariffs usually encompass three periods (red - amber - green) when the prices are different. Higher price is at peak time (red period) and lower price is during green period. The structure of the tariff is adopted for the calculation of prices, however the prices only account for the price of the commodity to obtain the same average price as the one for flexible electricity generation. The values and structure are presented in [5].
Whilst in pilot scale this feeding regime is represented by only one pulse feed every $24 \mathrm{~h}$, at demonstration scale two feeding regimes are tested:

- The first feeding regime spread across 24 hourly feeds per day the two thirds of the total daily volume and the remaining third is added to one pulse feeding event at the beginning of the red period.

- The second feeding regime also spread two thirds of the daily volume over the 24 hourly feeds, however the last third is spread over the $3 \mathrm{~h}$ of the red period.

The design of these feeding regimes is driven by the demand defined by the red peak period.

\section{Flexible Generation}

In GB, the main market-based short-notice balancing service is the Balancing Mechanism (BM). The performance criteria to trade active power on the BM define flexible generation in this study. The analysis of the BM is made on data from its administrator, Elexon Ltd [24], over the entire period when market prices' calculation methodology was based on the marginal 50 MW (Price Average Reference-PAR50). This period was between November 5th, 2015 and November 4th, 2018.

The analysis of the BM clearly shows a high degree of volatility and variability of prices (Fig. 3). The objective is to have $\mathrm{AD}$ to support such fluctuations in demand for generation by making biogas available during peak periods. Therefore, the combination of highest prices and the length of multiple consecutive peaks constitutes an opportunity for demand-driven biogas production.

Two kind of peaks are identified on the BM [5]:

- Daily peaks, the half-hours with highest prices in a day, and

- Absolute peaks, when the price is above the threshold of average wholesale unit cost for an industrial user [25].

The calculation of the feeding regimes in hourly feeding needs to include the length of daily and absolute peaks periods. The methodology for the definition of the daily peaks is previously presented [5], and the optimum number of highest-priced daily half-hours to constitute peak times is 15 . By capturing these half-hours the valorisation of the biogas is maximum, reaching a value of $£ 50.32 / \mathrm{MW} \cdot \mathrm{h}$ as opposed to an average $£ 46.28 / \mathrm{MW} \cdot \mathrm{h}$. This means that the flexible electricity generation and consequently the demanddriven biogas production need to target the 7 and half hours in a day with the highest prices. However, they may not occur consecutively. 
Fig. 3 Variability and volatility of prices on the BM in the PAR50 period. Data sourced from [24]. Figure reproduced from [5] with permission

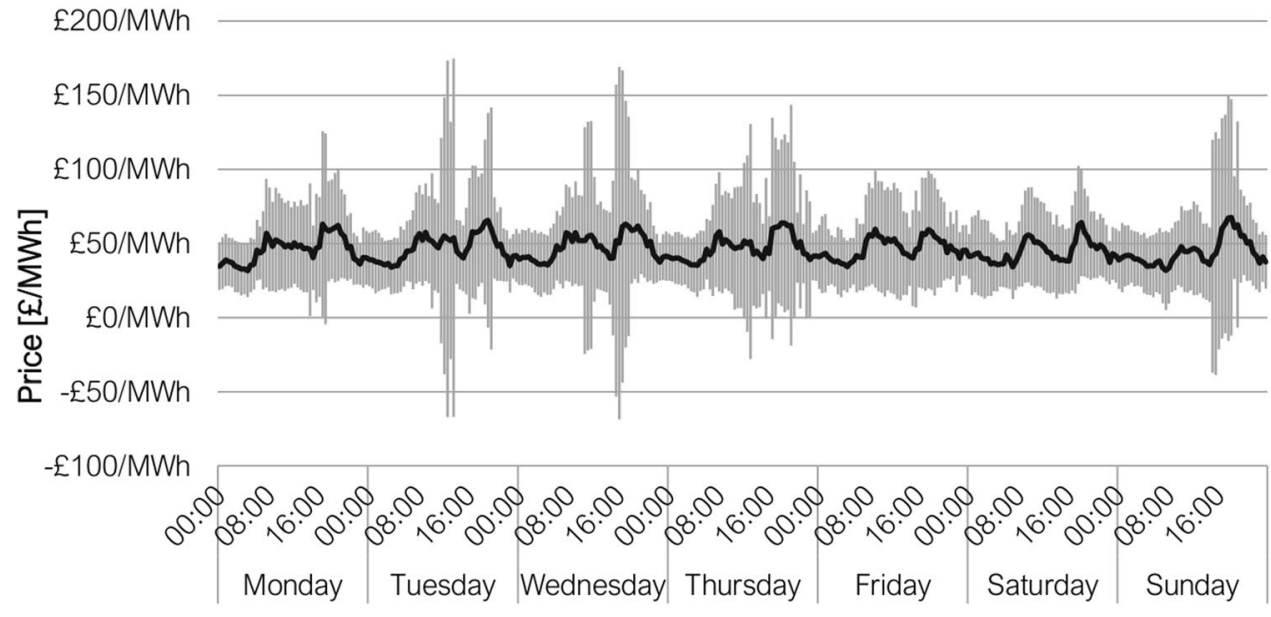

The occurrence of consecutive half-hours being peaks is an opportunity. Therefore, daily and absolute peaks are analyzed according to the likelihood of occurrence in periods of different length. Accordingly, peaks are classified as:

- Single peak (i.e. next half-hours are not defined as peaks);

- Short period (i.e. a peak that lasts for up to one hour and half);

- Long period (i.e. when the length is between two hours and four hours);

- Very long period (i.e. a peak period of more than four consecutive hours).

In GB, both daily (Fig. 4a) and absolute peaks (Fig. 4b) are more likely to occur in morning and early evening hours. Although daily peaks can occur at any time of the day, absolute peaks are extremely rare during the night. Relevant peak periods that last more than a single halfhour are likely to occur during the morning (from 7:30 to $13: 30$ ) and during afternoon and evening hours (from 16:00 to 21:00).

Summarizing, both daily and absolute peaks are likely to occur in similar periods of the day, which represents an opportunity for demand-driven biogas production as it is possible to plan feeding regimes in advance, according to the likelihood of occurrence of peaks.

The combined analysis of daily and absolute peaks defines two kind of peak periods:

- A morning period, spread over several hours and with less likelihood of occurrence, and

- An afternoon peak period spread on a narrow timeframe and with high likelihood of occurrence.
Fig. 4 Distribution by length of peak periods during the PAR50 period, data from Elexon [24]

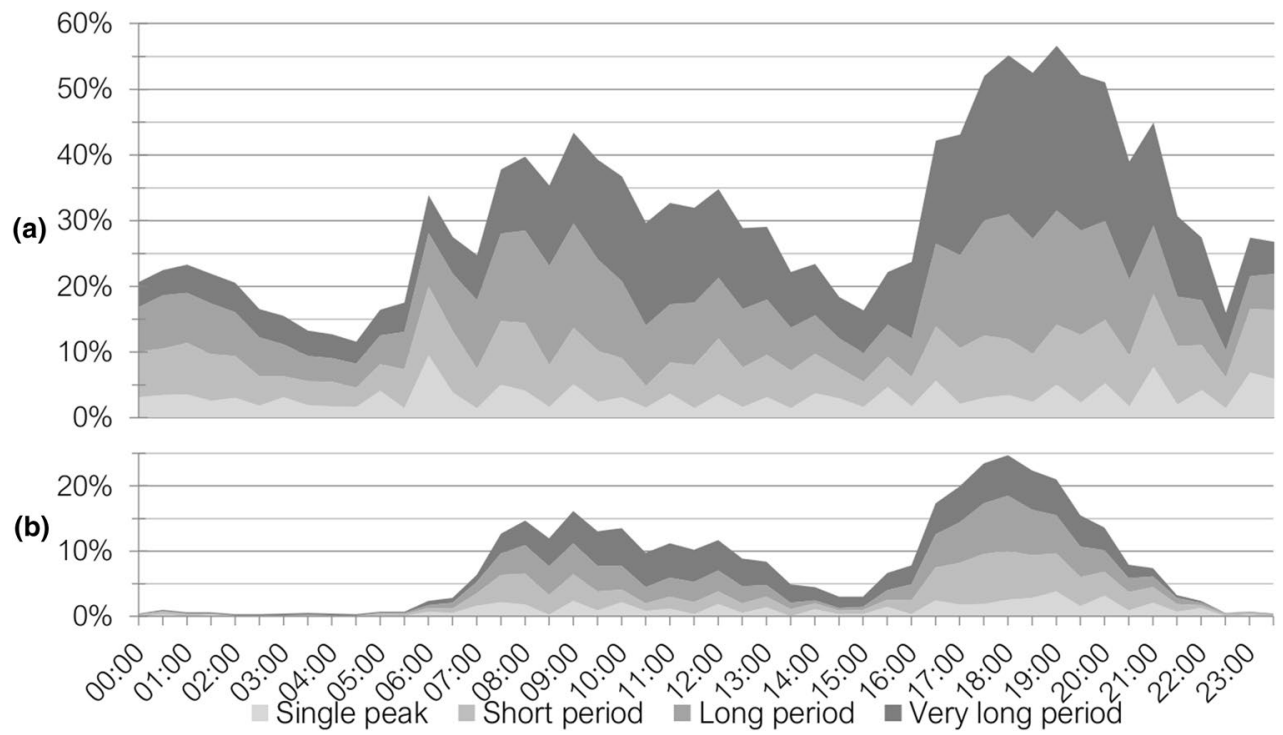




\section{The Definition of the Demand-Driven Feeding Schedules}

Given STWs need energy both in the form of electricity and heat on a continuous basis and sewage sludge needs to be treated continuously, demand schedules are defined daily. Two demand schedules are defined in this study, which will constitute the reference for the feeding regimes of $\mathrm{AD}$ :

- CPPA-driven schedule: one peak period per day, from 16:00 to 19:30;

- BM-driven schedule: two peak periods per day, from 8:00 to 11:00 and from 16:30 to 21:00.

The demand-driven feeding schedules are compared with a steady state feeding regime. The hourly organic loading in this condition is maintained by the operator constant.

\section{Results}

\section{Performance and Stability Under Pulse Feeding}

The reactor T4 is fed according to the BM-driven schedule, as pulse feeds occurring at 8:00 and 16:00. However, differently from pilot scale, the feeding event takes around $25 \mathrm{~min}$. This is a significant difference with pilot scale experiments, and likely to occur also in full industrial scale.

Figure 5 shows the biogas production rate from the demand-driven feeding regime during the experimental period. The organic loading varies as expected, considering the HRT is fixed but the substrate characteristics vary (as shown in section Biochemical characteristics). The increasing organic loading reflects possible acidification occurring while the substrate is stored between the time it is imported and then fed to the reactor.

The performance of the reactor is consistent with reference values for a similar case tested at pilot scale [5]. In the whole experimental period, $\mathrm{DSD}=34 \%$,
$\mathrm{VSD}_{\text {MASS BALANCE }}=48 \%$ and $\mathrm{VSD}_{\mathrm{VAN} \mathrm{KLEECK}}=50 \%$. The biogas yield is $444 \mathrm{~m}^{3} / \mathrm{t}_{\mathrm{DS}}$ or $593 \mathrm{~m}^{3} / \mathrm{t}_{\mathrm{vS}}$. Although transitional imbalances occur after the feed, the ratio of VFAs and total alkalinity is 0.16 on average, representing a 'healthy' condition. The concentration of ethanoic acid is never found to be above $300 \mathrm{mg} / \mathrm{l}$ and its ratio with the concentration of propanoic acid is 0.14 on average, also representing a 'healthy' condition.

The results show that the biogas production rate can match the demand when following a demand-driven feeding regime. The response of the increase in biogas production rate from the reactor is immediate at the end of the feeding event. The readily digestible matter is likely processed by the $\mathrm{AD}$, which returns a significant increase of biogas production rate. Additionally, the length of the increased biogas production rate meets the length of the peak periods for flexible electricity generation (Sect. Dispatchable Generation).

The results from this pulse feeding experiment reveal that the behaviour and results obtained in pilot scale are replicable in demonstration scale, despite the different operational configuration of the reactors at the two scales.

\section{Performance Under Semi-Continuous Feeding}

Four feeding regimes designed on hourly feeding events are tested by operating the reactor $\mathrm{T} 5$ in order to investigate the performance of demand-driven feeding regimes in operational conditions like those more often found at full scale. The experimental conditions and the performance results are summarised in Table 1, and presented in the following sub-sections.

\section{Steady Feeding Regimes}

Figure 6 presents the organic loading and biogas flow under the steady feeding regime.

Whilst operators aim to maintain the feeding regime as steady as possible, small variations of the organic loading
Fig. 5 Organic loading and biogas flow from the pulse feeding experiment

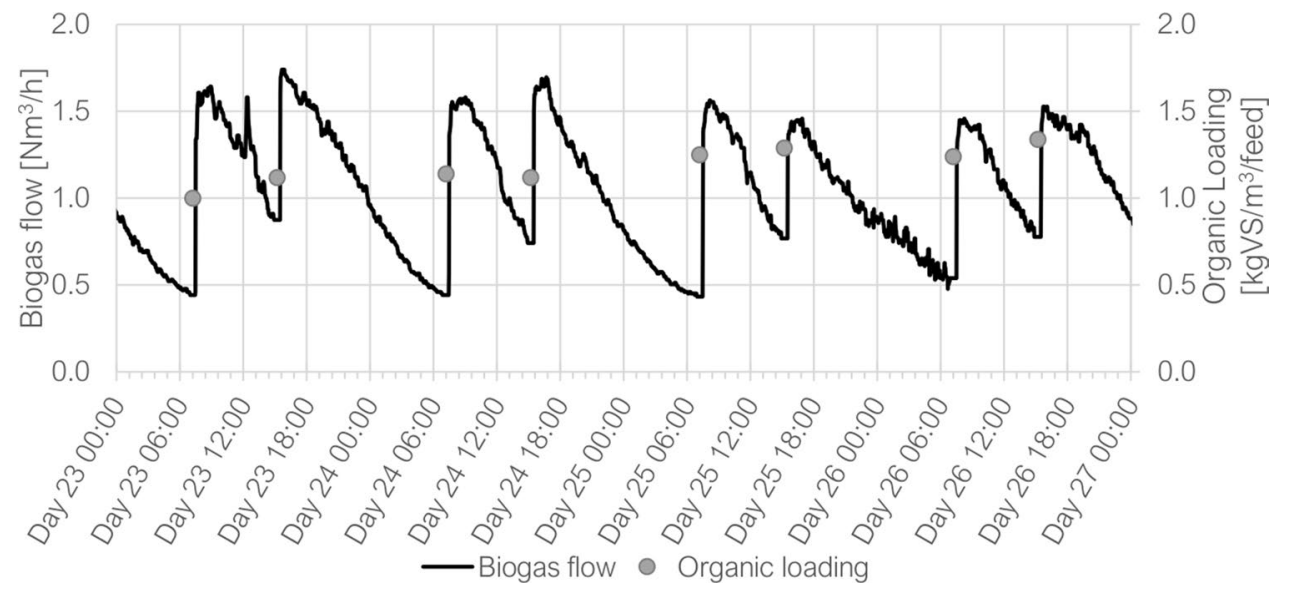


Table 1 Overview of performance parameters of experiments in demonstration scale

\begin{tabular}{|c|c|c|c|c|c|c|}
\hline \multirow[t]{2}{*}{ Experiment } & \multirow{2}{*}{$\begin{array}{l}\text { DSD } \\
{[\%]}\end{array}$} & \multirow{2}{*}{$\begin{array}{l}\mathrm{VSD}_{\mathrm{MB}} \\
{[\%]}\end{array}$} & \multirow{2}{*}{$\begin{array}{l}\mathrm{VSD}_{\mathrm{VK}} \\
{[\%]}\end{array}$} & \multicolumn{2}{|l|}{ Biogas yield } & \multirow{2}{*}{$\begin{array}{l}\text { Biogas value } \\
\text { [£/MW·h] }\end{array}$} \\
\hline & & & & {$\left[\mathrm{m}^{3} / \mathrm{tDS}_{\mathrm{fed}}\right]$} & {$\left[\mathrm{m}^{3} / \mathrm{tVS}_{\mathrm{fed}}\right]$} & \\
\hline Steady 24-hourly feeds per day & 33 & 43 & 44 & 423 & 588 & $£ 46.28$ \\
\hline Concentrated CPPA-based & 32 & 44 & 44 & 442 & 620 & $£ 47.25$ \\
\hline Spread CPPA-based & 35 & 47 & 45 & 434 & 575 & $£ 46.50$ \\
\hline BM-driven & 35 & 47 & 45 & 452 & 599 & $£ 46.71$ \\
\hline
\end{tabular}

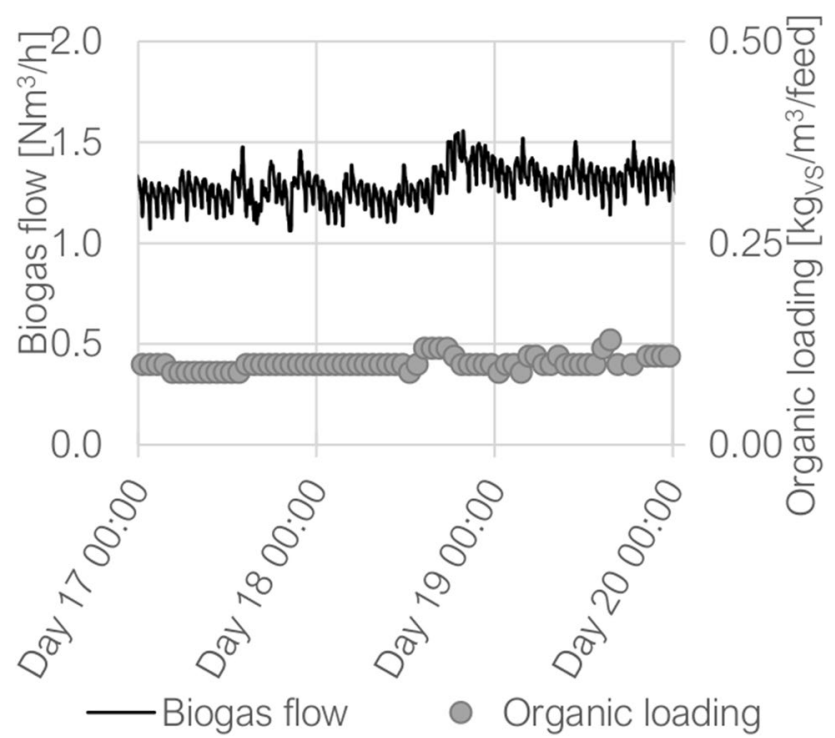

Fig. 6 Organic loading and biogas flow during experiments under steady feeding regime

are observed. For example, the organic loading varies by up to $0.02 \mathrm{~kg} \mathrm{vs} / \mathrm{m}^{3} /$ feed during the period shown in the figure. The biogas production rate noticeably responds to such variations, as shown in Fig. 6.

Additionally, the biogas flow varies in the period between two consecutive feeds. It is possible to observe an increase in biogas production rate after the feed, a peak and a decrease. This recurrent trend is observed despite sudden variations in biogas flow that may occur because of specific events, such as a variation in pressure caused by the feed of substrate or withdrawal of digester sludge, or maintenance activities.

Under a steady feeding regime, the performance indicators report $\mathrm{DSD}=33 \%, \mathrm{VSD}_{\mathrm{MASS}}$ BALANCE $=43 \%$ and $\mathrm{VSD}_{\mathrm{VAN} \text { KLEECK }}=44 \%$. The biogas yield is $423 \mathrm{~m}^{3} / \mathrm{t}_{\mathrm{DS}}$ or $588 \mathrm{~m}^{3} / \mathrm{t}_{\mathrm{vs}}$.

Assuming a storage of the biogas before its utilisation for electricity generation would accommodate for the small hourly variations and produce a baseload generation, the value of the biogas in this scenario is $£ 46.28 / \mathrm{MW} \cdot \mathrm{h}$.

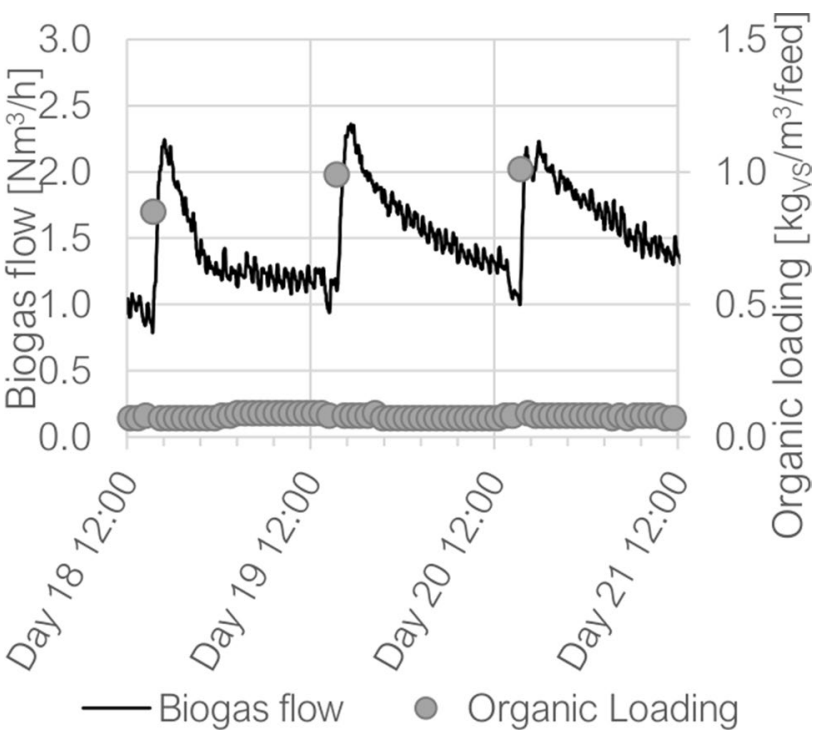

Fig. 7 Organic loading and biogas flow under the CPPA-driven feeding regime, concentrating the peak-time feed volume in one feeding event

\section{Concentrated CPPA-Driven Feeding Regime}

Full scale digesters are generally fed continuously or in batches at short interval. As mentioned in the Sect. Introduction, the storage of large volumes of sewage sludge before treatment is not realistic, however some storage is generally found at several stages between sewage treatment processes, sewage sludge treatment processes and AD.

The CPPA-driven feeding regime is tested according to the calculation presented in Sect. Calculation of Feeding Regimes.

Figure 7 shows the organic loading and biogas flow under the first experiments under the CPPA-driven feeding regime. In this case two thirds of the total daily volume are spread across 24 hourly feeds and the remaining third is added to one pulse feeding event at the beginning of the red period.

Although the daily feeding volume is spread in hourly feeds, under this feeding regime the peak time 'input signal' is concentrated. The response is immediate after the feeding event and lasts for several hours. In addition to the larger increased due to the peak-time feed, each hourly feed 
produces a local peak (i.e. increase and decrease in biogas production rate within the hour before the following feed).

Overall performance parameters are similar to the results under the baseline steady state feeding regime. The DSD $=32 \%, \mathrm{VSD}_{\text {MASS BALANCE }}=44 \%$ and $\mathrm{VSD}_{\mathrm{VAN} \mathrm{KLEECK}}=44 \%$. The biogas yield is higher than the steady feeding regime, resulting in $442 \mathrm{~m}^{3} / \mathrm{t}_{\mathrm{DS}}$ or $620 \mathrm{~m}^{3} / \mathrm{t}_{\mathrm{vS}}$.

Following this feeding regime, assuming the biogas storage would only average the biogas flow within each halfhour, the average value of the resource calculated over the whole experimental period in this scenario is $£ 47.25 / \mathrm{MW} \cdot \mathrm{h}$, which represents an increase by $2 \%$ if compared with the steady-state generation scenario.

\section{Spread CPPA-Driven Feeding Regime}

The CPPA-driven feeding regime more likely to be implemented in full scale is presented in Fig. 8. In this case, the peak-load (i.e. the one third of the total daily feeding volume) is spread over the length of the peak period. The 'input signal' is reduced in comparison with the other CPPA-driven feeding regime and spread in several feeding events.

A significant increase in biogas production rate is achieved within one hour after the beginning of the peak period. At the end of the feeds covering the peak period, the biogas production rate appears to maintain high levels and slowly deceasing until the following peak period, exceeding the length of the peak period.

The weaker 'signal' observed reflects in the flexibilisation performance. In fact, the value of the biogas is $£ 46.50$ / $\mathrm{MW} \cdot \mathrm{h}$, higher by less than $1 \%$ than steady generation. This modest increase is however consistent with the expected

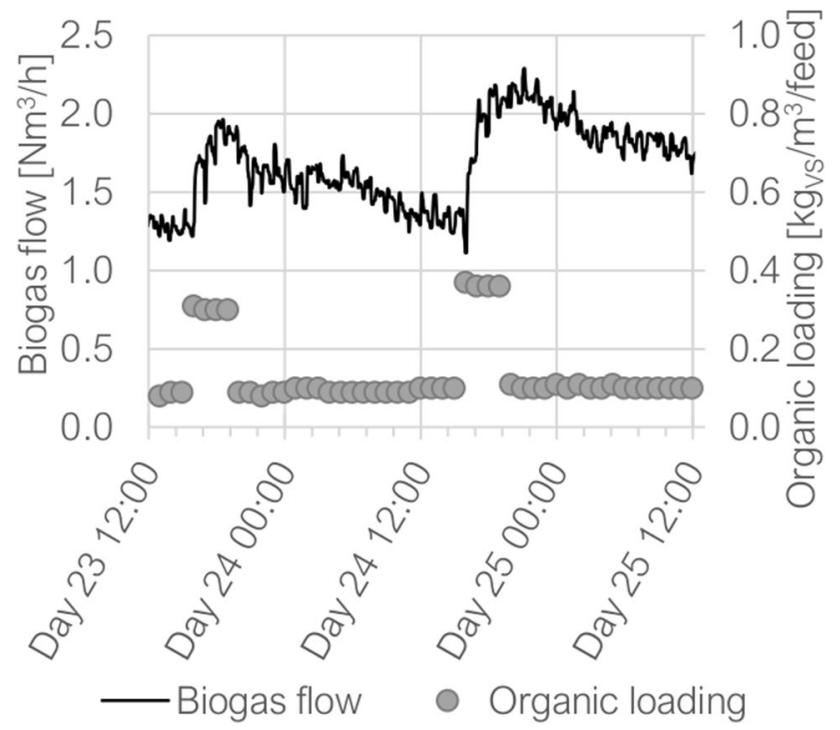

Fig. 8 Organic loading and biogas flow under the CPPA-driven feeding regime, spreading the peak-time volume to cover the red period increase found in pilot scale results [5], considering the lower concentration of the 'input signal' than pulse feeding.

The performance parameters depict a contrasting condition. While the DSD and VSD are higher by between 1 and $3 \%$ than the concentrated CPPA-driven feeding regime, the biogas yield is lower by $2 \%$. In particular, the $\mathrm{DSD}=35 \%$, $\mathrm{VSD}_{\text {MASS BALANCE }}=47 \%$ and $\mathrm{VSD}_{\mathrm{VAN} \mathrm{KLEECK}}=45 \%$ while the biogas yield is $434 \mathrm{~m}^{3} / \mathrm{t}_{\mathrm{DS}}$ or $575 \mathrm{~m}^{3} / \mathrm{t}_{\mathrm{vs}}$. However, the performance is higher than the benchmark steady feeding regime.

\section{BM-Driven Feeding Regime}

Results from the BM-driven feeding regime that aims to support flexible electricity generation for trading in balancing services are presented in Fig. 9. The final test of the BM-driven feeding regime similarly spread two thirds of the total daily volume over 24 hourly feeding events, and the remaining third over the peak time studied in Sect. Dispatchable Generation.

Under this feeding regime the flexibilisation performance is weaker than when concentrating the 'input signal'. Whilst the response is fast (the increase is observed within $1 \mathrm{~h}$ from the increased feed) and the length matches the length of the peak periods, the value of the biogas is $£ 46.71 / \mathrm{MW} \cdot \mathrm{h}$, which represent an increase by $1 \%$ in value in comparison with the benchmark. This magnitude is also consistent with pilot scale figures [5]. As opposed to the concentrated CPPAdriven feeding regime, the biogas production rate does not appear to have a clear correlation with the increased feed and in some instances the rate does not decrease when the organic loading decrease, as shown in Fig. 9. Additionally,

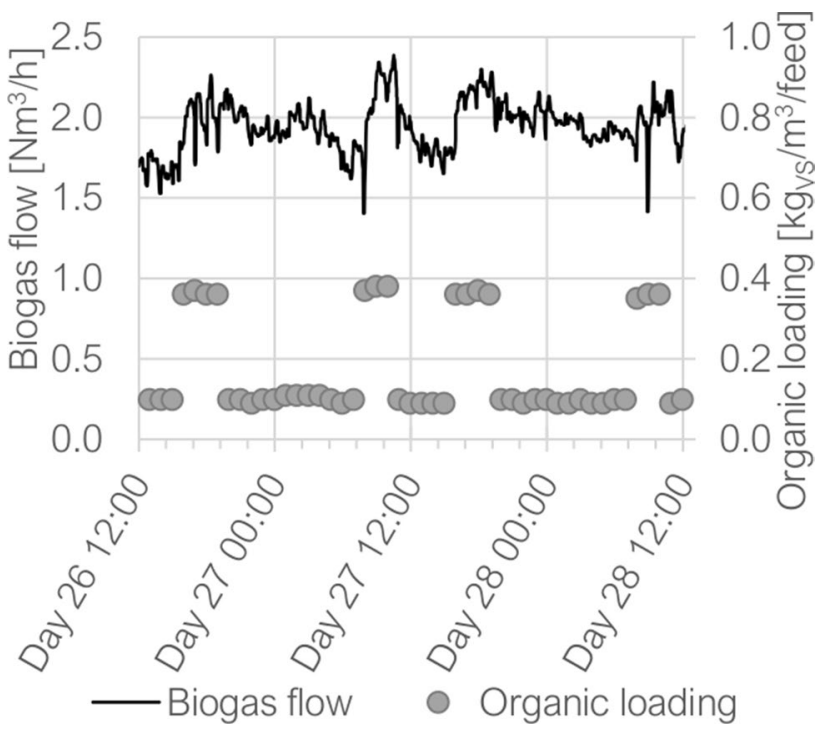

Fig. 9 Organic loading and biogas flow under the BM-driven feeding regime 
the demonstration scale $\mathrm{AD}$ and the results appear susceptible of major and minor operational differences. In addition to the mixing quality (that will be shown in "Stability and operational parameters under semi-continuous feeding" Sect. as an example of a major operational singularity), minor and regular operational singularities are observed to vary the biogas production. For example, the increase in biogas production presented in Fig. 9 on Day 17 after 00:00 (and similarly on Day 28) could be the consequence of the occurrence of the heating cycle.

On the contrary, the performance parameters are higher than the results under the baseline steady state feeding and in the other feeding regimes. The DSD $=35 \%$, $\mathrm{VSD}_{\text {MASS BALANCE }}=47 \%$ and $\mathrm{VSD}_{\mathrm{VAN} \mathrm{KLEECK}}=45 \%$. The biogas yield is $452 \mathrm{~m}^{3} / \mathrm{t}_{\mathrm{DS}}$ or $599 \mathrm{~m}^{3} / \mathrm{t}_{\mathrm{VS}}$.

\section{Stability and Operational Parameters Under Semi-Continuous Feeding}

As expected from literature $[7,21]$ and pilot experiments [5], transitional imbalances are observed regularly after the peak-time feeds. Figure 10 shows several occurrences of the transitional imbalances after a peak-time feed under the CPPA-driven feeding regime. However, parameters were occasionally outside of respective healthy ranges and the stability of the process naturally restored within two hours after the feed. Feeding regimes close to pulse feeding (i.e. when the 'input signal' is more concentrated) result in higher imbalances. Under these feeding regimes, sc-VFAs concentration is observed being higher than the 'healthy' threshold for up to four hours after the peak time. The average over the whole experimental period of ammoniacal-N is $1154 \mathrm{mg} / \mathrm{l}$, never above the threshold of stability [5], $\mathrm{pH}$ is 7.6. At the end of the 24-h cycles, the VFA concentration is $752 \mathrm{mg} / \mathrm{l}$ and the FOS/TAC ratio 0.18, while the ethanoic acid concentration $262 \mathrm{mg} / \mathrm{l}$ and the ethanoic/propanoic acids ratio 0.22 .

The foam level was variable, however contained in the standard headspace of the reactor. In the experimental period, the average level was $0.11 \mathrm{~m}$ in $0.50 \mathrm{~m}$ of headspace (see Fig. 10). The level of foam often increases after the beginning of peak time feeding and it reduced afterwards. Only one major foaming event was recorded in the experimental period and was caused by a failure of the SCADA system that led to erratic feed and overload of the reactor. These two are recognised by the literature as critical cause of foaming [8]. Overall, the results demonstrate that the foam level can be controlled, and its volume contained in the headspace.
Fig. 10 Foam level and stability parameters during the concentrated CPPA-driven feeding regime experiments. The peak time feeds occur daily at 16:00 and transitional imbalances occur afterwards. Partially reproduced from [5] with permission

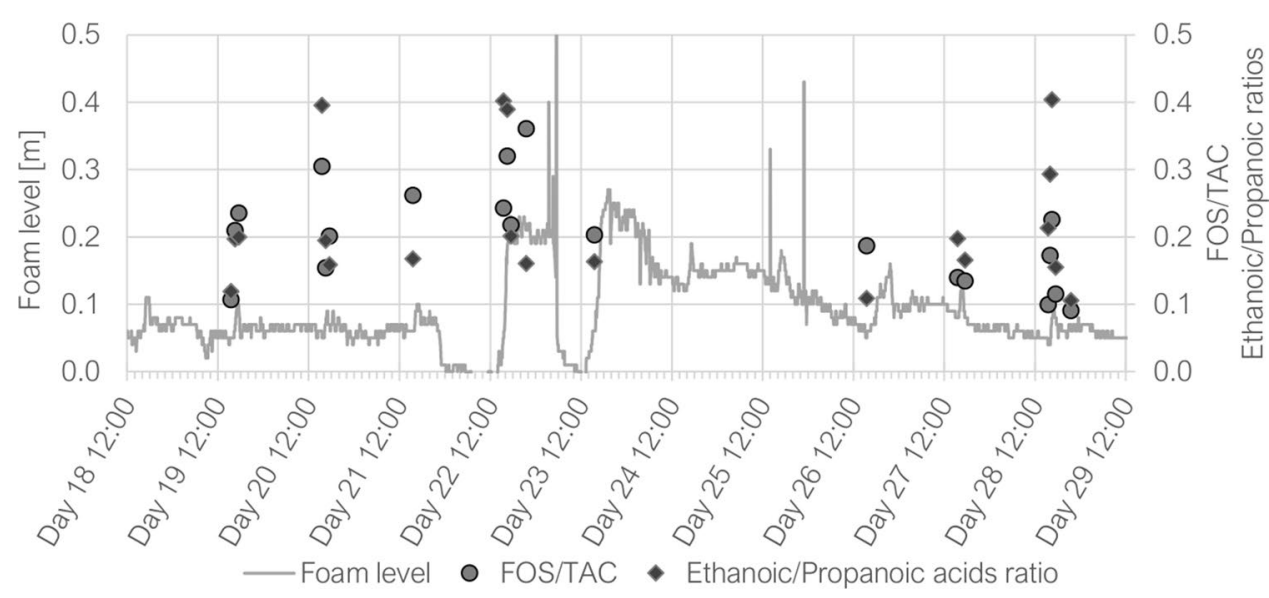

Fig. 11 Organic loading and biogas flow under the CPPAdriven feeding regime, at the occurrence of a failure of mixing (shaded period)

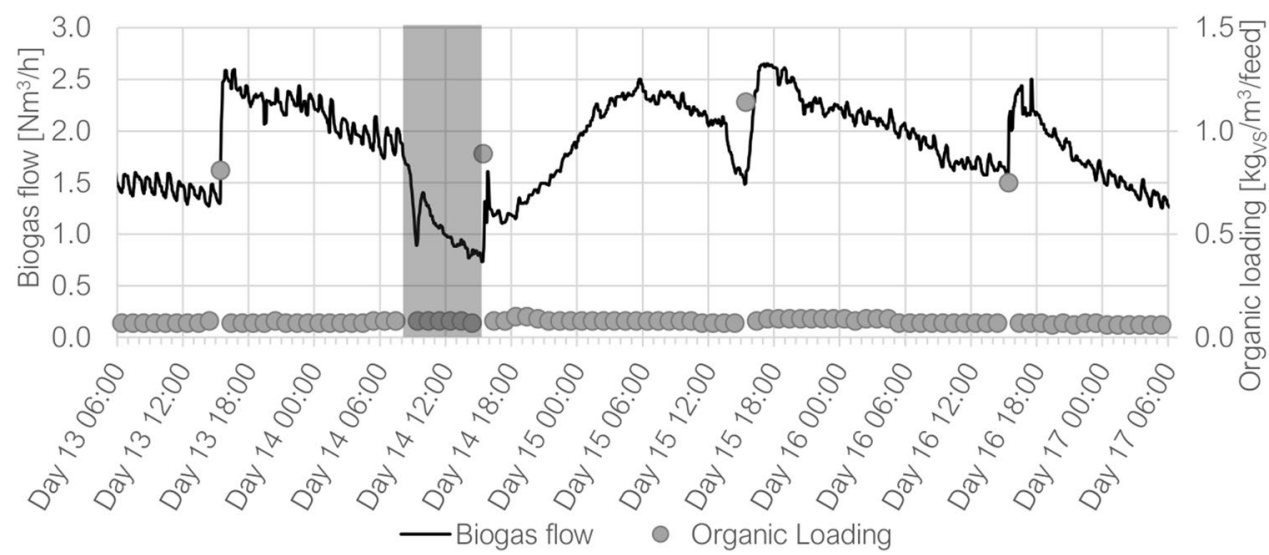


The biogas production rate appears closely affected by the mixing. Whilst continuous mixing fosters homogeneous distribution of substrate and microorganisms, on some occasions the mixing pump failed for technical reasons, and the mixing stopped. For example, Fig. 11 shows an immediate drop in the biogas flow and rapid decrease afterwards. This decrease is exacerbated by the inhibition of a feeding event while the withdraw was not inhibited. The inhibition is caused by the increase in foam level, possibly as a consequence of the failure of the mixing itself. When the mixing is restored (immediately before the peak-time feed shown in Fig. 11), the biogas production rate slowly increases, eventually reaching similar levels as the ones expected in peak time. The shift of the biogas production from red period to green period represents a financial risk, therefore operational conditions should be maintained constant during the day. However, whilst the interruption of mixing for several hours is not a suggested operational solution and the phenomena observed should be studied in detail, this unfortunate event suggests that the mixing power and quality could be regarded as operational parameter to obtain a dynamic biogas production rate.

\section{Discussion}

The experimental activities at demonstration scale presented in this work validate the technical potential of demanddriven biogas production from sewage sludge established in pilot scale. The response is within the expected period, as the increase in biogas production rate occurs within one hour from the beginning of the peak-time feed.

The biogas production rate increases at peak time under all demand-driven feeding regimes. The comparison with the steady feeding regime shows that the value increase in all scenario, although in some by a modest margin. Under pulse feeding, or concentrated feeding regimes, the increase in biogas production rate is more evident, which reflects on the increase in value and validates the results obtained in the pilot scale experimental work [5]. Additionally, the results obtained in this work confirm the expected reduced opportunity when upscaling from pilot scale to larger scale observed in the literature [7,26].

Whilst capital investments may be required to operate a full-scale plant under pulse or concentrated feeding, the additional capital or operational investment in operating the digesters under the feeding regimes presented in Sects. Concentrated CPPA-Driven Feeding Regime and Spread CPPADriven Feeding Regime is minimal. Therefore, the increase in value fully reflects in operational savings that are possible to obtain.

The biogas yield under demand-driven feeding regimes results being on average higher by $4 \%$ than the benchmark scenario. Albeit the substrate is inherently different between the period the $\mathrm{AD}$ is operated under the benchmark steady feeding regime or the demand-driven feeding regimes, this feeding regime appears to increase also the total biogas recovered by an unit of organic mass, confirming the observation already made at pilot scale [5]. Whilst the average HRT is maintained equal to an even distribution of the feed over a $24 \mathrm{~h}$ period (i.e. steady feeding regime), demanddriven feeding regimes locally increase the HRT because of the uneven distribution of the feed over a $24 \mathrm{~h}$ period. This is a possible contributing factor in the increase in biogas yield observed.

In conclusion, the demand-driven operation of $\mathrm{AD}$ appears to be scalable in full scale operational conditions.

The successful demonstration of the operational solution in a relevant environment is preparatory for full scale application. The different responses observed under the different feeding regimes will need to be investigated in full scale, considering the potential weak 'signal' when the input is not concentrated. Full scale application could be limited by asset and extra capacity availability; however, the process performance and stability are not expected to be adversely affected by demand-driven feeding schedules. Continuous and adequate mixing appears to be an important requisite for better and successful operation of the process.

\section{Conclusions}

This work investigated the application in a relevant operational environment of a modern operational approach to increase the valorisation of the biogas produced by $\mathrm{AD}$ of sewage sludge. Feeding regimes designed in order to match the demand return a variable biogas production rate that increases the value of the resource.

The successful implementation of demand-driven feeding regimes in conventional $\mathrm{AD}$ of sewage sludge suggests the scalability to implementation at full scale. As this work at demonstration scale was made in conventional $\mathrm{AD}$, a specific assessment for advanced $\mathrm{AD}$ might be required. However, conventional AD is known to be a more stressful operational condition for the process than advanced AD.

The operational innovation suggested in this work (i.e., feeding the digesters following appropriately calculated feeding regimes to obtain a dynamic biogas production which match the demand) is demonstrated to be feasible in a relevant operational environment. Therefore, the implementation at full-scale is technically viable and recommended as a future option. Future work might also encompass the development of appropriate industry-friendly tools to inform and support the application at full-scale.

Demand-driven feeding regimes can return operational savings by using current assets. Although the higher values 
are obtained under feeding regimes that may require capital investments to be implemented at full scale, holding tanks available at STWs are usually designed to store similar amounts of sewage sludge as the ones used in this study. However, a detailed STW-specific assessment of benefits and requirements is needed, including the assessment of the whole sewage sludge-to-electricity generation system. While this work focusses on the technical viability of demanddriven biogas production, both gas storage and the characteristics of the combined heat and power units contribute to the final flexibilisation of the system.

Acknowledgements The authors would like to thank Andrea Gysin and Paul Fountain for supporting the trials, and Manocher Asaadi, Peter Winter, Obinna Molokwu, Alex Gray, Ben Morris and Mark Poole for their assistance during the experimental activities. The authors gratefully thank the WasteEng2020 reviewers for their comments to the paper. Permission from ELEXON Limited as data's Intellectual Property Holder to use BMRS, BSC Website and ELEXON Portal data is gratefully acknowledged.

Authors' Contributions ML Conceptualization, Methodology, Validation, Formal analysis, Investigation, Resources, Data curation, Writing — original draft, Writing - review \& editing, Visualization, Project administration. RBT Conceptualization, Methodology, Writingreview \& editing, Visualization, Supervision, Funding acquisition. SKO Conceptualization, Methodology, Writing-review \& editing, Supervision, Funding acquisition. AS Methodology, Writing-review \& editing, Visualization, Supervision. EG Conceptualization, Methodology, Resources, Writing - review \& editing, Supervision, Funding acquisition. MW Methodology, Writing—review \& editing, Supervision. JL Conceptualization, Writing—review \& editing, Supervision, Funding acquisition.

Funding This research was funded by Thames Water Utilities Limited with the support of the UK Engineering and Physical Sciences Research Council (Grant Number EP/G037612/1).

Data Availability The datasets generated during and/or analysed during the current study are not publicly available due to their commercial sensitivity but are available from the corresponding author (ML) on reasonable request and with the permission of Thames Water Utilities Ltd.

Code availability Code availability not applicable to this article as no programs were generated during the study presented in this study.

\section{Declarations}

Conflicts of interest The authors have no conflicts of interest to declare that are relevant to the content of this article.

Open Access This article is licensed under a Creative Commons Attribution 4.0 International License, which permits use, sharing, adaptation, distribution and reproduction in any medium or format, as long as you give appropriate credit to the original author(s) and the source, provide a link to the Creative Commons licence, and indicate if changes were made. The images or other third party material in this article are included in the article's Creative Commons licence, unless indicated otherwise in a credit line to the material. If material is not included in the article's Creative Commons licence and your intended use is not permitted by statutory regulation or exceeds the permitted use, you will need to obtain permission directly from the copyright holder. To view a copy of this licence, visit http://creativecommons.org/licenses/by/4.0/.

\section{References}

1. Mills, N., Pearce, P., Farrow, J., Thorpe, R.B., Kirkby, N.F.: Environmental \& economic life cycle assessment of current \& future sewage sludge to energy technologies. Waste Manage. 34(1), 185-195 (2014). https://doi.org/10.1016/j.wasman.2013.08.024

2. Francini, G., Lombardi, L., Freire, F., Pecorini, I., Marques, P.: Environmental and cost life cycle analysis of different recovery processes of organic fraction of municipal solid waste and sewage sludge. Waste and Biomass Valorization. 10(12), 36133634 (2019). https://doi.org/10.1007/s12649-019-00687-w

3. Szarka, N., Scholwin, F., Trommler, M., Fabian Jacobi, H., Eichhorn, M., Ortwein, A., et al.: A novel role for bioenergy: a flexible, demand-oriented power supply. Energy 61, 18-26 (2013). https://doi.org/10.1016/j.energy.2012.12.053

4. National Grid ESO: Electricity trading. https://www.nationalgr ideso.com/industry-information/balancing-services/trading (2020). Last accessed: October 12th 2020.

5. Lafratta, M., Thorpe, R.B., Ouki, S.K., Shana, A., Germain, E., Willcocks, M., Lee, J.: Dynamic biogas production from anaerobic digestion of sewage sludge for on-demand electricity generation. Biores. Technol. 310, 123415 (2020). https://doi. org/10.1016/j.biortech.2020.123415

6. Lutze, R., Rühl, J., Schaum, C., CornelFrom sewage sludge treatment to demand-driven energy supply using an anaerobic membrane digester. IWA Holistic Sludge Management, P.: Malmö, p. 2016. IWA, Sweden (2016)

7. Mauky, E., Weinrich, S., Jacobi, H.-F., Nägele, H.-J., Liebetrau, J., Nelles, M.: Demand-driven biogas production by flexible feeding in full-scale - Process stability and flexibility potentials. Anaerobe 46, 86-95 (2017). https://doi.org/10.1016/j.anaerobe. 2017.03.010

8. Ganidi, N., Tyrrel, S., Cartmell, E.: Anaerobic digestion foaming causes - A review. Biores. Technol. 100(23), 5546-5554 (2009). https://doi.org/10.1016/j.biortech.2009.06.024

9. Rus, E., Mills, N., Shana, A., Perrault, A., Fountain, P., Thorpe, R.B., et al.: The intermediate thermal hydrolysis process: results from pilot testing and techno-economic assessment. Water Practice and Technology. 12(2), 406-422 (2017). https://doi.org/10. 2166/wpt.2017.031

10. Mills N. Unlocking the Full Energy Potential of Sewage Sludge. Centre for Environmental Strategy. Guildford, UK: University of Surrey; 2015. p. 117.

11. British Standards Institute. BS EN ISO 15970:2014: Natural gas. Measurement of properties. Volumetric properties: density, pressure, temperature and compression factor. British Standards Institute; 2008.

12. British Standards Institute: BS EN ISO 14532:2017: Natural gas. Vocabulary, British Standards Institute (2017)

13. Harris, A.T., Davidson, J.F., Thorpe, R.B.: The influence of the riser exit on the particle residence time distribution in a circulating fluidised bed riser. Chem. Eng. Sci. 58(16), 3669-3680 (2003). https://doi.org/10.1016/S0009-2509(03)00215-X

14. Subramanian, B., Pagilla, K.R.: Anaerobic digester foaming in full-scale cylindrical digesters - Effects of organic loading rate, feed characteristics, and mixing. Biores. Technol. 159, 182-192 (2014). https://doi.org/10.1016/j.biortech.2014.02.089

15. Wilson, C.A., Tanneru, C.T., Banjade, S., Murthy, S.N., Novak, J.T.: Anaerobic digestion of raw and thermally hydrolyzed 
wastewater solids under various operational conditions. Water Environ. Res. 83(9), 815-825 (2011)

16. Ferguson, R.M.W., Coulon, F., Villa, R.: Organic loading rate: a promising microbial management tool in anaerobic digestion. Water Res. 100, 348-356 (2016). https://doi.org/10.1016/j. watres.2016.05.009

17. Standing Committee of Analysts. Determination of the $\mathrm{pH}$ value of sludge, soil, mud and sediment; and lime requirement of soil. 1977. Methods for the Analysis of Waters and Associated Materials. London: Her Majesty's Stationery Office; 1978.

18. Standing Committee of Analysts. Determination of Volatile Fatty Acids in Sewage Sludge, 1979. Methods for the Analysis of Waters and Associated Materials. London: Her Majesty's Stationery Office; 1980.

19. The Met Office: Weather forecast in Basingstoke (Hampshire). https://www.metoffice.gov.uk/weather/forecast/gcp5x5uz2 (2019). Last access: November 30th 2019.

20. Gerardi, M.H.: The microbiology of anaerobic digesters. John Wiley, Hoboken, N.J. (2003)

21. Mulat, D.G., Jacobi, H.F., Feilberg, A., Adamsen, A.P.S., Richnow, H.-H., Nikolausz, M.: Changing feeding regimes to demonstrate flexible biogas production: effects on process performance, microbial community structure, and methanogenesis pathways. Appl. Environ. Microbiol. 82(2), 438-449 (2016)
22. Switzenbaum, M.S., Farrell, J.B., Pincince, A.B.: Relationship between the van kleeck and mass-balance calculation of volatile solids loss. Water Environ. Res. 75(4), 377-380 (2003). https:// doi.org/10.2175/106143003X141187

23. Hahn, H., Krautkremer, B., Hartmann, K., Wachendorf, M.: Review of concepts for a demand-driven biogas supply for flexible power generation. Renew. Sustain. Energy Rev. 29, 383-393 (2014). https://doi.org/10.1016/j.rser.2013.08.085

24. ELEXON Limited. ELEXON Portal. https://www.elexonportal. co.uk/ Last accessed: October 12th 2020

25. Department for Business Energy \& Industrial Strategy (BEIS) Digest of UK Energy Statistics 2019. London, 2019.

26. Dotzauer, M., Pfeiffer, D., Lauer, M., Pohl, M., Mauky, E., Bär, K., et al.: How to measure flexibility - Performance indicators for demand driven power generation from biogas plants. Renewable Energy 134, 135-146 (2019). https://doi.org/10.1016/j.renene. 2018.10.021

Publisher's Note Springer Nature remains neutral with regard to jurisdictional claims in published maps and institutional affiliations.

\section{Authors and Affiliations}

\section{Mauro Lafratta ${ }^{1,2}$ D $\cdot$ Rex B. Thorpe ${ }^{3} \cdot$ Sabeha K. Ouki $^{4} \cdot$ Achame Shana $^{5} \cdot$ Eve Germain $^{2} \cdot$ Mark Willcocks $^{6}$. Jacquetta Lee ${ }^{1}$}

Mauro Lafratta

m.lafratta@surrey.ac.uk

1 Centre for Environment and Sustainability, University of Surrey, Guildford GU2 7XH, UK

2 Research, Development and Innovation, Thames Water Utilities Ltd, Reading STW, Reading RG2 0RP, UK

3 Department of Chemical and Process Engineering, University of Surrey, Guildford GU2 7XH, UK
4 Department of Civil and Environmental Engineering, University of Surrey, Guildford GU2 7XH, UK

5 Operational Excellence, Thames Water Utilities Ltd, Clearwater Court, Vastern Road, Reading RG1 8DB, UK

6 Energy and Carbon, Thames Water Utilities Ltd, Clearwater Court, Vastern Road, Reading RG1 8DB, UK 